\title{
Asphalt Pavement Performance in Extreme Weather Events in Tropical Country
}

\author{
Pham Viet Hung \\ Faculty of Engineering and Technology \\ Hue University, Hue city, \\ Vietnam
}

\author{
Nguyen Thi Thanh \\ Faculty of Engineering and Technology \\ Hue University, Hue city, \\ Vietnam
}

\begin{abstract}
In the tropical climatic countries like Vietnam, Thailand..., for the last few years, the air temperature often raises up to $42.7^{\circ} \mathrm{C}$ and thus it heated up the asphalt pavements to $75^{\circ} \mathrm{C}$. Additionally, more torrential prolonged raining often occurs at high temperature. In such the extreme weather, a large increase in asphalt pavement distresses such as rutting, shoving, slippage and potholes happened often with both of the new and normally used highway pavements. These asphalt pavement distresses are costly and decreasing serviceability of highways.

The study was conducted to interpret the behavior of asphalt highway pavements under the extreme weather conditions with consideration of different aggregate types, HMA gradation, varying temperature and immersion time. Two series of the Indirect Tensile Tests (ID) and the series of Unconfined Compression Tests (UC) were analyzed to check the behavior of asphalt pavements due to the temperature, water, and aggregate type superposition. The study carried out two series of ID tests and $\mathrm{UC}$ tests under wide ranges of temperatures varied from $25^{\circ} \mathrm{C}, 45^{\circ} \mathrm{C}, 60^{\circ} \mathrm{C}$ and $75^{\circ} \mathrm{C}$ and under ranges of immersion time varied from 40 minutes, 24 hours, 72 hours and 120 hours at $60^{\circ} \mathrm{C}$. Based on the on-site observations and the experimental data, asphalt pavement deterioration was evaluated, and paper recommends the remedies to reduce the distress of the asphalt pavement.
\end{abstract}

Keywords-Asphalt Highway Pavement; Temperature; Water; Climate Change; Deteriorations

\section{INTRODUCTION}

Temperature and water can impact the properties of the asphalt pavement layers, making them susceptible to accelerated damage to traffic loading, reducing their serviceable lifespan, and increasing maintenance costs, all of which would have a major negative impact on the nation's economy. Increase from asphalt pavement temperature as a result of rising air temperature and reduction in asphalt pavement modulus due to high rainfall, flooding, sea levels are all factors that should be considered designing and construct asphalt pavements that will perform under nonstationary future climate conditions [4]. Vietnam is one of the countries that the asphalt pavement design refers to the standard of America or Europe, of which the standards were produced from the experimental database of totally different climate zones. To directly employ the design standard of one place to another may not be always appropriate [6]. It is, therefore, indispensable to check for important climatic associated factors such as temperature, precipitation, where cold climate countries environment is significantly different from those in the tropical zone and develop adaptation asphalt pavements under non-stationary future climate conditions, particularly in local coastal areas, based on lessons learned from pavement failures and problems experienced during the last few years in Vietnam.

\section{OVERVIEW ON ASPHALT PAVEMENT FAILURE AND WEATHER CONDITIONS}

\section{A. Asphalt pavements in the extreme weather events}

Tropical countries like Vietnam locates on the tropical typhoon belt and severely affected by climate change and thus the response to climate change is of the crucial importance of Vietnam, particularly the North Central Coastal (NCC) region that has a high temperature and abundant precipitation. People observe the rises in average temperatures as well as substantial changes to precipitation patterns over the last decades during the rainy seasons over the last decades. Vietnam's temperature and precipitation trends have been greatly different among regions during the last 50 years. The annual average temperature has increased by $0.5^{\circ} \mathrm{C}$ nationwide. Maximum daily precipitation has increased in almost all regions, particularly during recent years. Several days with heavy rain seems to have increased similarly, with significant changes in the central regions [9]. The air temperature, on May 30th, 2015 at many places in the region, raised up to $30-40^{\circ} \mathrm{C}$, especially at Con Cuong (Nghe An province) raised up to $42.7^{\circ} \mathrm{C}$ and thus heated up the $1 \mathrm{~A}$ national highway asphalt pavements to $73^{\circ} \mathrm{C}$ [11]. Under this extreme weather conditioning, the distress of asphalt pavements as rutting happened in the $1 \mathrm{~A}$ national highway even in pavements that had served well before the extreme climatic conditions occurred as showed in the Figure. 1 (a). According to Ministry of Transportation, in the sections of 1A National Highway (from Km 223m to $\mathrm{Km} 232$ and from Km $387+$ $100 \mathrm{~m}$ to $\mathrm{Km} 709+400$ ), slipping and cracking occurs $8 \%$ of the total damage to the pavement surface. From the beginning year of 2014 on National Highway 1A (from Thanh Hoa province to Thua Thien Hue province), the pavement rutting was observed on $70 \mathrm{~km}$ of a total $620 \mathrm{~km}$, of which $13 \%-15 \%$ of rutting pavements had been paved for six years. The most subsidence has happened during the intense air temperature days [8].

In terms of tropical cyclones, there are about seven storms affecting Vietnam annually, five of which hit or directly affect the country's mainland. In the NCC region (from $16^{\circ} \mathrm{N}$ to $\left.18^{\circ} \mathrm{N}\right)$, the storms or tropical depressions occur most often along the coastal region, with a storm or tropical depression landfall every 2 years in average with a very high rainfall with a standard deviation from annual rainfall about $400 \mathrm{~mm}$ $700 \mathrm{~mm}$ [9]. The region received a record-breaking amount of rainfall up to 747 millimeters within 24 hours, higher than the 
previous peak of 555 millimeters on October 9th, 1995. The asphalt pavements of the 1A national highway have been defenseless against continuous torrential rains in the two days. Damages of the asphalt pavement have also been observed even in new pavements as presented in the Figure. 1 (b). The 1A Highway across Thua Thien Hue province (from Phu Bai district to Bac Hai Van district) has been upgraded, expanded and exploited more than a year has damaged and appeared many "potholes" after a long period of heavy rain. The phenomenon of which asphalt pavements have been stable in a long time to be suddenly distressed in the "extreme temperature" days or to be devastated after long rains as mentioned above, remained a question on the role of environmental factors [10].

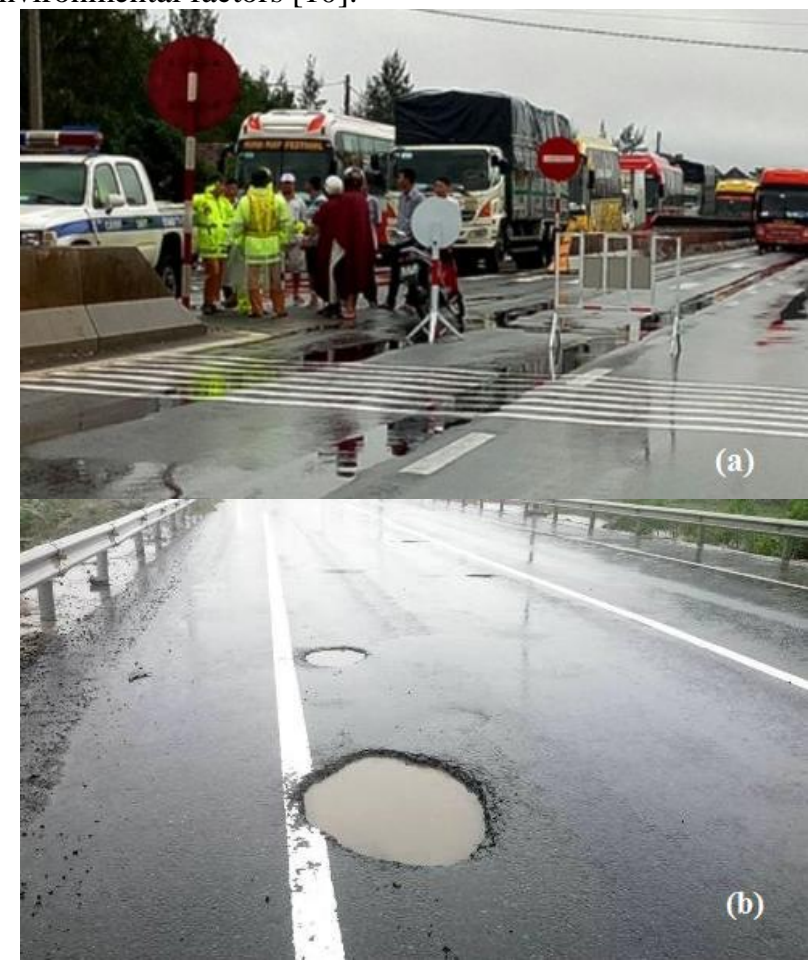

Figure 1. Rutting (a) and potholes (b) observed in 1A Highway in the extreme weather conditions in NCC region of Vietnam

\section{B. Extreme weather events due to Climate change scenarios} of temperature and precipitation

Climate change and sea level rise scenarios developed for Vietnam are based on different greenhouse gas emission scenarios of IPCC's 4th report (IPCC 2007), namely a low emission scenario (B1), medium emission scenarios (B2, $\mathrm{A} 1 \mathrm{~B})$, and high emission scenarios (A2, A1F1)[3].
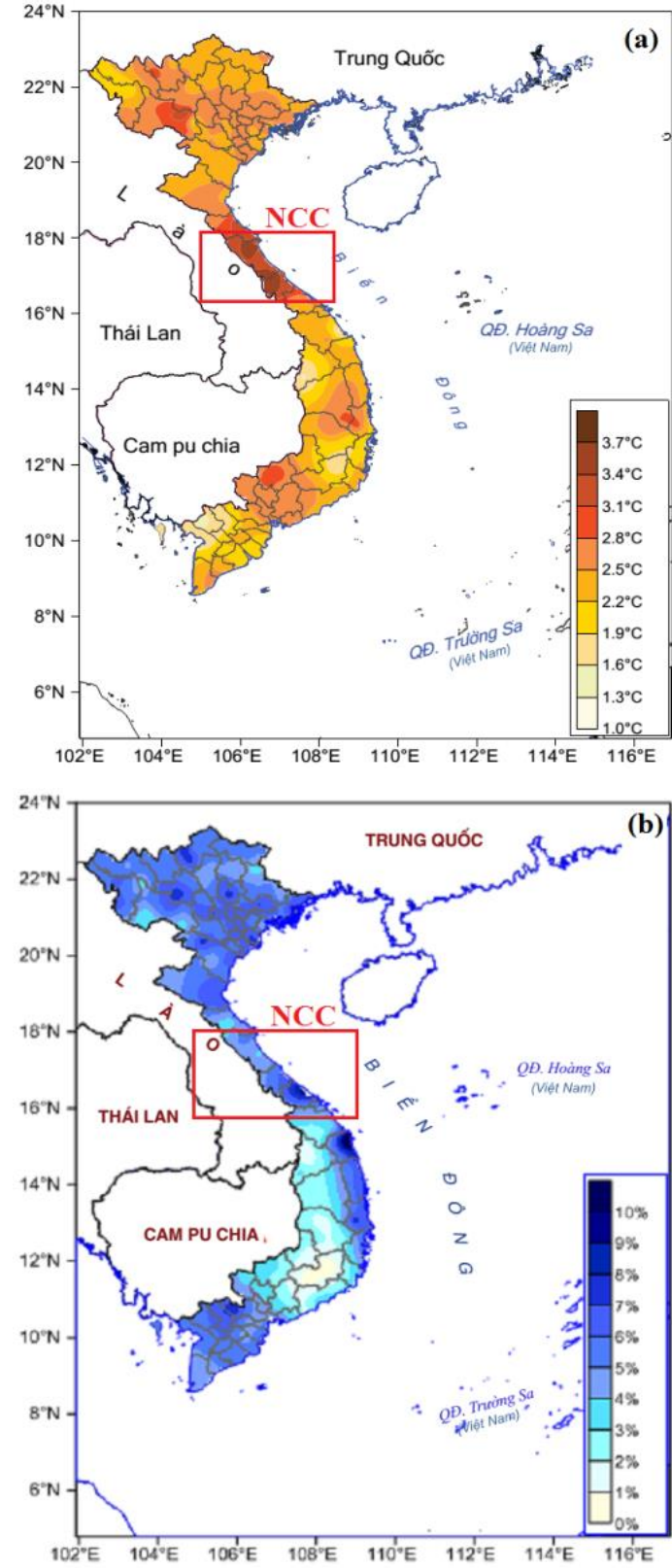

Figure 2. Change in the temperature (a) and precipitation (b) for the medium emission scenarios at the end of 21 st century [9]

Climate change scenarios of temperature and precipitation are developed for seven climate regions in Vietnam: North West, North East, Northern Delta, North Central Region, South Central Region, Central Highlands, and Southern Region. Annual average temperatures at the end of $21 \mathrm{st}-$ century increase by $3{ }^{\circ} \mathrm{C}$ for $\mathrm{B} 2$. Annual precipitation at the end of 21 st-century increases by $2-7 \%$ for B2. Based on the medium emission scenario B2, the temperature and precipitation increased highly to the NCC region from Nghe An province $\left(18^{\circ} \mathrm{N}\right)$ to Thua Thien Hue province $\left(16^{\circ} \mathrm{N}\right)$ is as in Figure 2(a) and Figure 2 (b), respectively. In the figures, the annual temperature increases by $3{ }^{\circ} \mathrm{C}$ and the annual precipitation increases by $10 \%$. It means that climate change induced extreme weather events will continuously be one of the significant challenges to the strength of asphalt highway pavements in the future. 


\section{MATERIALS AND METHODS}

\section{A. Material characterization}

The materials employed to make Hot Mix Asphalt (HMA) specimens in this study are designed according to the Marshall method. All of these materials were practically used for 1A national highway construction in NCC Region of Vietnam.

Aggregate is the major structural framework of asphalt mixture to absorb and control different stresses on the pavement. Table 1 presents name of specimens. Specimen QB_HMA, QT_HMA, and TTH_HMA corresponding three types of aggregates to be quarried from Quang Binh (QB) province, Quang Tri (QT) province, and Thua Thien Hue (TTH) province in the NCC region. These aggregate types are known having the different temperature and water sensitive. The nominal maximum size of aggregate is $12.5 \mathrm{~mm}$ and 19 $\mathrm{mm}$. The sieve size diagram for wearing course is according to TCVN8818-2011 Standard as in Figure. 3.

TABLE I. PROPERTIES OF AGGREGATES

\begin{tabular}{|l|l|l|l|}
\hline Location & $\begin{array}{c}\text { Type of } \\
\text { Aggregate }\end{array}$ & $\begin{array}{c}\text { Compression } \\
\text { Strength (MPa) }\end{array}$ & $\begin{array}{c}\text { Specimen } \\
\text { Name }\end{array}$ \\
\hline TTH & Marble & 80 & TTH_HMA \\
\hline QT & Granite & 101 & QT_HMA \\
\hline QB & Limestone & 79 & QB_HMA \\
\hline
\end{tabular}
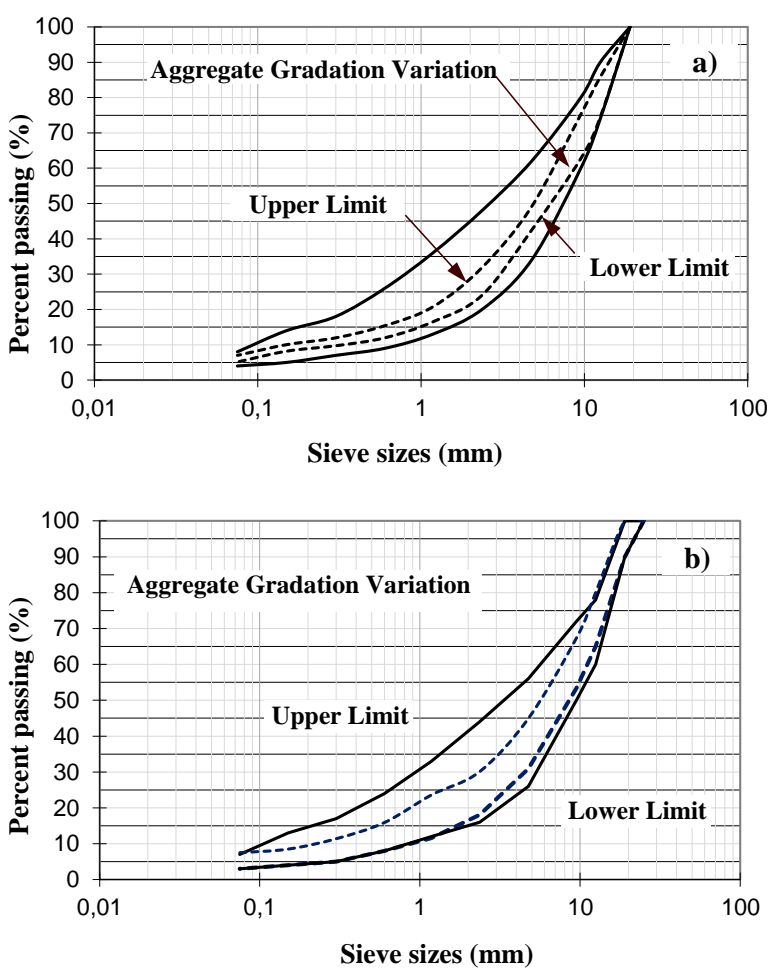

Figure 3. Sieve size diagram of Aggregate gradation of (a) $12.5 \mathrm{~mm}$ specimens and (b) $19 \mathrm{~mm}$ specimens

Asphalt Shell bitumen 60/70 commonly used in the region was selected for this research. The properties of bitumen were shown in Table 2 .

TABLE II. PROPERTIES OF BINDER

\begin{tabular}{|l|l|l|}
\hline \multicolumn{1}{|c|}{ Properties } & \multicolumn{1}{c|}{ Unit } & \multicolumn{1}{c|}{ Average } \\
\hline Penetration Grade at $25 \mathrm{C}$ & $1 / 10 \mathrm{~mm}$ & 64 \\
\hline Softening point $\left({ }^{\circ} \mathrm{C}\right)$ & ${ }^{\circ} \mathrm{C}$ & 52 \\
\hline Kinematic Viscosity $\left(60^{\circ} \mathrm{C}\right)$ & Pa.s & 191 \\
\hline Specific Gravity & - & 1.031 \\
\hline
\end{tabular}

\section{B. Test Methods}

Concerning the rutting phenomenon, the rate and depth of rutting depend on many factors [7]. The factor noticed as the most effective parameter of rutting is the characteristics of aggregates. HMA properties are highly affected by their aggregate characteristics [1]. The rut resistance is "highly dependent on aggregate grading", and that mixes made with the best possible materials would fail in a proper gradation [8]
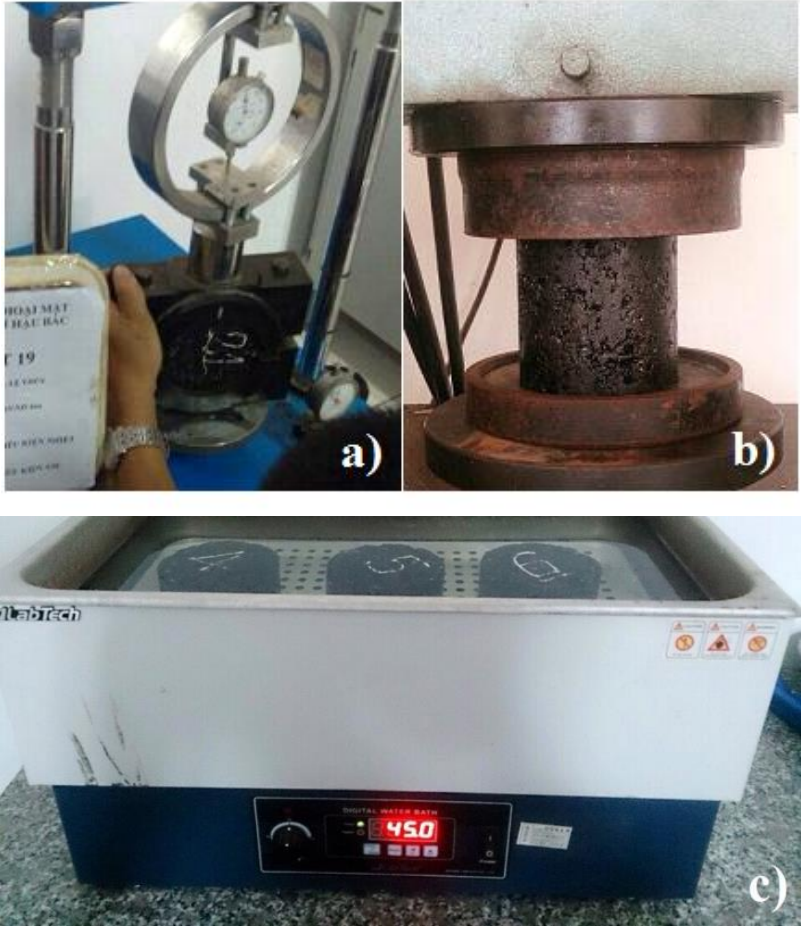

Figure 4. Experimental setup for (a) ID test, (b) UC test and (c) electrical immersion water bath

In order to interpret the behavior of asphalt pavements structures under the regional extreme weather, taking into account temperature, water, aggregate gradations and types as the important factors influencing the structural strength of highway asphalt pavements. Thus, the goal of this study is to evaluate the behavior of asphalt concrete under the varying temperature and water immersion time with different aggregate types by using a series of Unconfined Compression Tests (UC) and Indirect Tensile Tests (ID) performed to failure.

Temperature is one of the major contributor to several types of distress. Therefore, the temperature is a significant factor that affects the performance of the pavement. A technique to explain the time - temperature superposition with growing damage based on the uniaxial compression constant rate test was proposed [5]. These tests aim to study the time temperature superposition of asphalt concrete, which is extended over the previous work and developed. The series of UC and ID tests were used to evaluate the behavior of asphalt concrete due to the temperature - water - aggregate superposition. The specimen dimension of the ID tests is 100 $\mathrm{mm}$ diameters with $65 \mathrm{~mm}$ height according to the Marshall method. The ID specimen is loaded with its diametric plane in the static condition. On the other hand, the specimen of 100 $\mathrm{mm}$ diameters with $150 \mathrm{~mm}$ height is prepared for the UC tests. The UC specimen is loaded with the specimen height of 
the static condition. The HMA specimens were compacted by Superpave Gyratory Compactor (SGC) which is controlled with a constant strain rate of $0.001 / \mathrm{sec}$ until failure. For each of the aggregate types, temperature or immersion time factors, a group of three specimens are investigated. These two test series were carried out under wide ranges of temperatures varied from $25^{\circ} \mathrm{C}$ (at night), $45^{\circ} \mathrm{C}$ (normal), $60^{\circ} \mathrm{C}$ (standard) and $75{ }^{\circ} \mathrm{C}$ (extreme weather condition) as presented in Table 3. The experimental conditions were designed based on the recent weather condition and climate change scenarios as mentioned before.

TABLE III.
EXPERIMENTAL CONDITIONING
\begin{tabular}{|c|c|c|c|c|}
\hline $\begin{array}{c}\text { Weather } \\
\text { Factors }\end{array}$ & Standard & \multicolumn{3}{|c|}{ Temp./Immersion Time } \\
\hline Temp. & $60^{\circ} \mathrm{C}$ & $25^{\circ} \mathrm{C}$ & $45^{\circ} \mathrm{C}$ & $75^{\circ} \mathrm{C}$ \\
\hline Water & 40 minutes & $24 \mathrm{~h}$ & $72 \mathrm{~h}$ & $120 \mathrm{~h}$ \\
\hline
\end{tabular}

Water has lots of adverse effects on asphalt pavement performance. Water damages can be defined as the loss of strength and durability in asphalt pavement caused by the presence of water. Hence, it's the need to correctly identify the problem and isolate issues of contributing factors like material variability and construction practices for a better understanding of water effect on pavement deterioration. The water damage is induced by the loss of the bond between the asphalt cement or the mastic and the fine and coarse aggregate. The tests of identifying the water sensitivity potential for an asphalt-aggregate mixture can be divided into two major categories based on mixture type: those on the loose mixtures and those on compacted mixtures [2]. Typical compacted mixture tests to include indirect tensile with the modulus and strength measurement, immersion-compression, abrasion weight loss, and sonic vibration tests. The major advantage of these compacted mixture tests is that the mixture physical and mechanical properties, water/traffic action, and pore pressure effects can be taken into account. The AASHTO Standard Method of Test T283, "Resistance of Compacted Bituminous Mixture to Water - Induced Damage," is one of the most commonly used procedures for determining HMA water susceptibility. In this study, the compacted specimens are brought to a constant temperature by a $60^{\circ} \mathrm{C}$ water bath for the different immersion time of 40 minutes, 24 hours, 72 hours and 120 hours as in Table 3. The electrical water bath for both ID and UC tests as in Figure 4-c.

\section{RESULTS AND DISCUSSIONS}

\section{A. HMA Specimens under Temperature Conditions}

\section{- Results of the ID tests}

Figure 4 shows the responses of the specimens with different types of aggregates at four temperatures in the ID tests. There are two general trends observed for the effect of aggregate types of stress. The first, TTH_HMA specimens and QB_HMA specimens show the same form of the stress reduction while the QT_HMA specimens show the less stress reduction of temperature $45{ }^{\circ} \mathrm{C}, 60{ }^{\circ} \mathrm{C}$ and $75{ }^{\circ} \mathrm{C}$. All HMA specimens have nearly same stress value of the lowest temperature $25^{\circ} \mathrm{C}$ (640 kpa in ID tests) then suddenly drops at $45{ }^{\circ} \mathrm{C}$ with the remained stresses of $64 \%$ and $36 \%$ for QT_HMA specimens and QB_HMA specimens, respectively.
The stresses lightly decrease from the temperature from $45^{\circ} \mathrm{C}$ to $60{ }^{\circ} \mathrm{C}$ but continue to decrease more at the higher temperature (at higher $60^{\circ} \mathrm{C}$ ). Note that the Vietnam Standard Design of asphalt pavements considers the temperature of 60 ${ }^{\circ} \mathrm{C}$ as the design temperature condition. Particularly, the TTH_HMA specimens and QB_HMA specimens decrease significantly with the remained stress of $17 \%$ while the QT_HMA specimens show the remained stress of $46 \%$ at the temperature of $75^{\circ} \mathrm{C}$. The result indicates that the aggregates do not significantly affect bond strength and failure mechanisms of asphalt-aggregate systems at low temperature. The QT aggregates show less temperature sensitive than others. The reason is that the compression strength of QT aggregate (around $101 \mathrm{kpa}$ ) is quite higher than the compression strength of TTH aggregate and QB aggregate (75-80 kpa). In the temperature conditioning of the higher pavement temperature observed in the field may need to rethink about temperature sensitivity of the temperature limit and aggregate types for the current asphalt concrete design code in the NCC region of Vietnam.

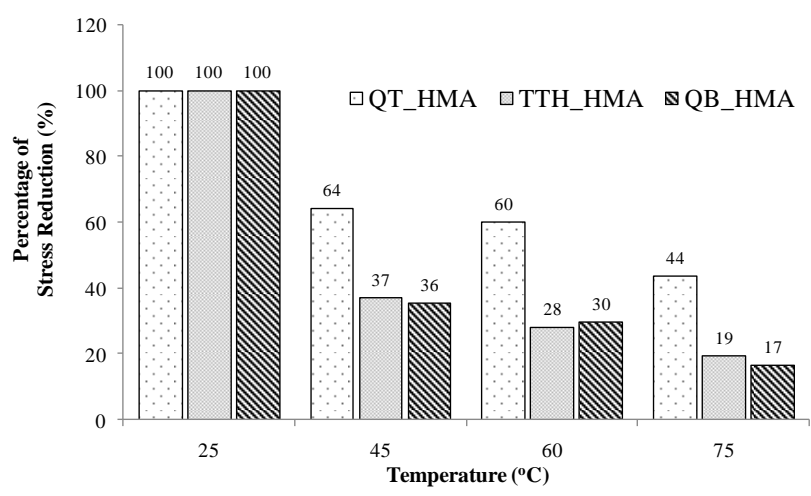

Figure 4. Stress reduction of $19 \mathrm{~mm}$ aggregate specimens versus temperature in the ID tests

Figure 5 shows popular subsidence of wheel tracks. As the air temperature rises, the surface temperature increases, the asphalt material from solid state to quenched and liquefied state, reduces the binding force between aggregate particles and vice versa.

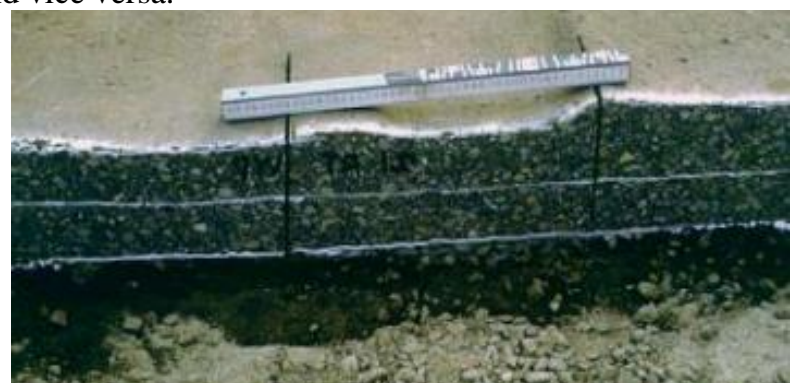

Figure 5. Cross-section of rutting asphalt highway pavement on site

- Results of the UC tests

In order to assess the stability of HMA subjected to high temperature conditions, the UC tests using the QT_HMA and QB_HMA specimens are analyzed. The results showed in Figure 6 pointed out that the effect of temperature on the compressive strength is quite similar. This shows that the ability to withstand the compression of vehicle axle load is 
similar to the two stones aggregation. The detail of QT_HMA $12.5 \mathrm{~mm}$ behavior is shown in Figure 7.

Based on the results of ID tests and UC tests, the first conclusion is that TTH_HMA and QB_HMA $19 \mathrm{~mm}$ gradation specimens are more stable than QT_HMA under shear stress in ID tests. The second conclusion is that HMA $12.5 \mathrm{~mm}$ gradation specimens are better under the compression stress. In another word, it is better for the top layer of asphalt pavement where it serves directly loads of vehicle wheel.

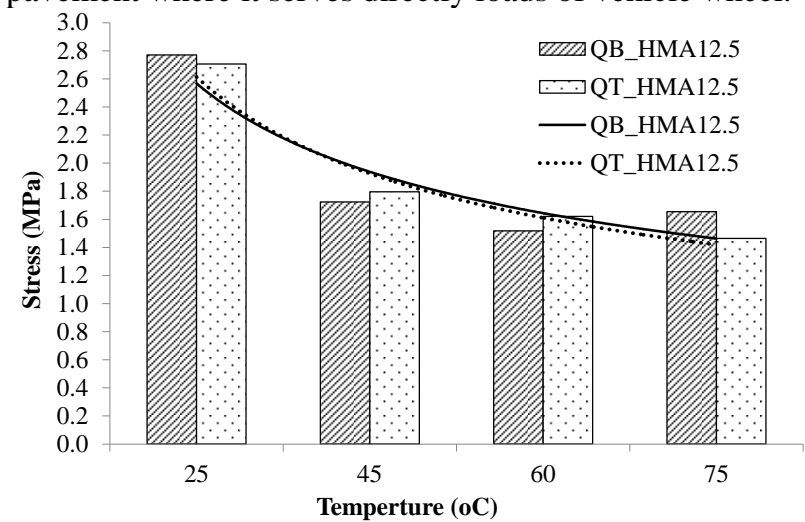

Figure 6. Stress of $12.5 \mathrm{~mm}$ aggregate specimens versus temperature in the

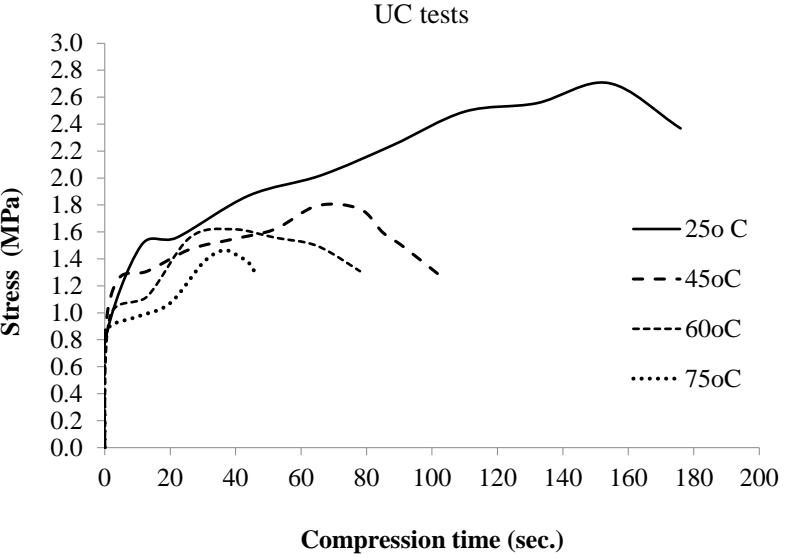

Figure 7. Stress of QT_HMA $12.5 \mathrm{~mm}$ aggregate specimens versus temperature in the UC tests

\section{B. HMA Specimens under Immersion Conditions}

Results of the ID tests

Figure 8 shows the responses from the specimens at the four periods of immersion times for both the ID with different types of aggregates. The water sensitivity of asphalt mixtures of different aggregate types subjected to the different water conditioning is evaluated based on the stress reduction comparisons. The characteristics of aggregates and immersion time greatly affect the bond strength and failure mechanisms of asphalt concrete. The tensile strength of all HMA specimens changed after water exposure. After 24-hour immersion conditioning, the strength of the specimens suddenly drops about $11 \%$ then lightly reduces from 24 hours to 72 hours. After 72 hours, the stress reduction of the QT_HMA specimens reduces more significantly than that of the TTH_HMA specimens and QB_HMA specimens. It means that the QT aggregates are more sensitive to water conditioning than that of TTH aggregates and QB aggregates. It can be interpreted that limestone aggregates and asphalt have a higher adhesive bond than that of granite aggregates, and thus more resistance to adhesive failure.

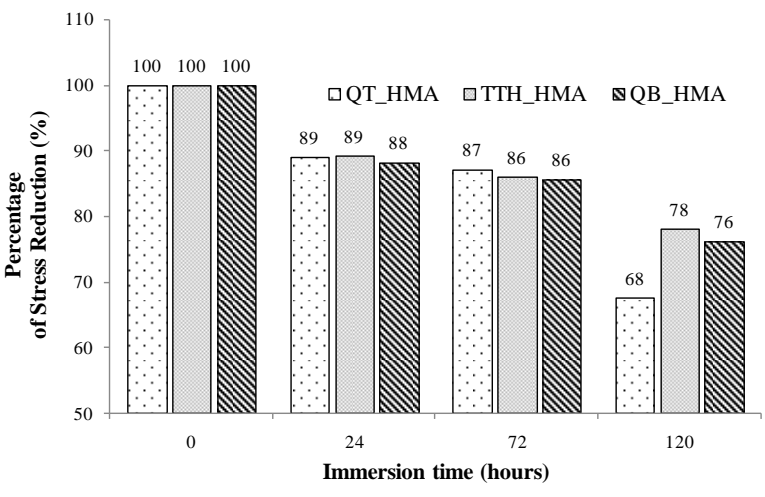

Figure 8 . Stress reduction of $19 \mathrm{~mm}$ aggregate specimens versus immersion time in the ID tests

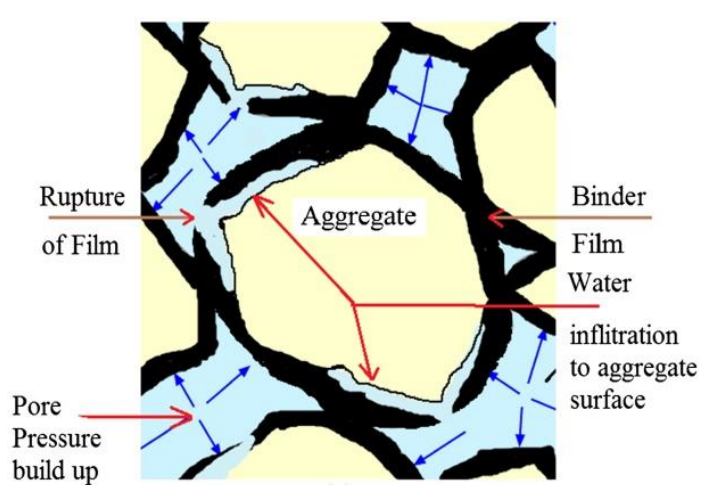

(a)

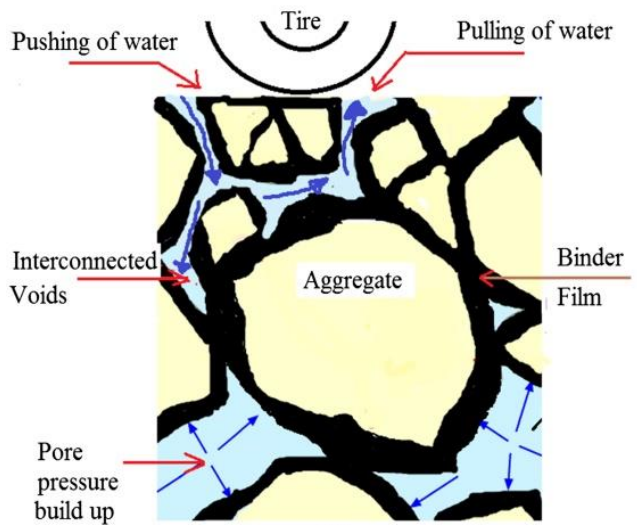

(b)

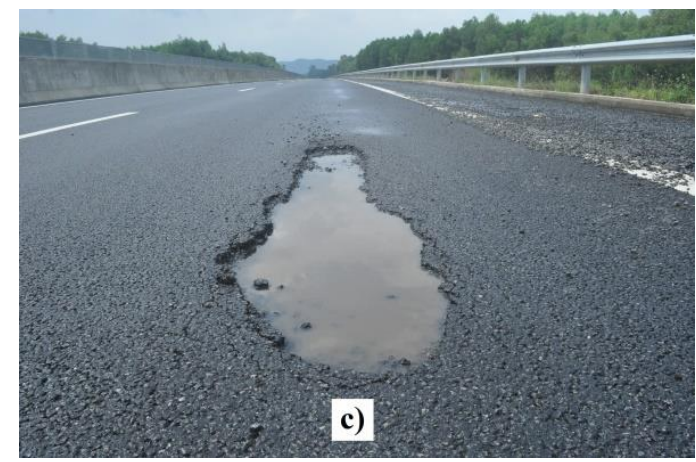

Figure 9. Deterioration Mechanism of Asphalt Pavement Subjected Extreme Water Conditions $(\mathrm{a}, \mathrm{b})$ and Pothole Failure on site

The highway asphalt pavement is also subject to longterm heavy rain, widespread flooding due to unusual storms. Under these conditions, due to existing microcracks, the 
thermal shrinkage, and axle load, HMA is often intruded by water, which makes the bitumen membrane - aggregates bond weakly, especially where the bitumen membrane defect is interrupted like Figure 9.a. Under the pressure of the wheel surface, the water is pressed into the cracks to create a hydraulic wedge, making the pore pressure increase, leading to asphalt material decaying as shown in Figure 9-b. As the wheel passes, it almost immediately absorbs water with the asphalt material decayed from the cracks causing loss of materials such as potholes, layer separation or surface honeycomb as in Figure 9-c.

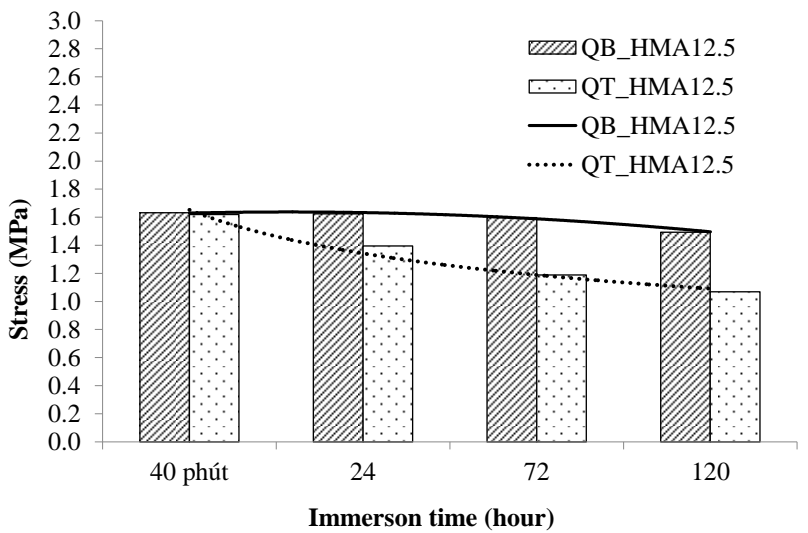

Figure10. Stress of $12.5 \mathrm{~mm}$ aggregate specimens versus immersion time in the UC tests

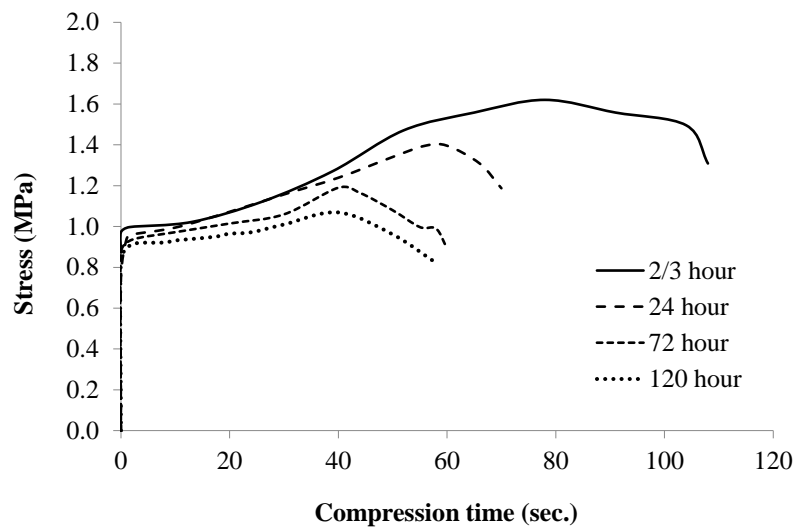

Figure 11. Stress of QT_HMA 12.5mm aggregate specimens versus temperature in the UC tests

- $\quad$ Results of the UC tests

The results of the UC tests show that the curve of stress versus immersion time of QT HMA specimens reduce more significantly than that of the QB_HMA specimens, especially in 120 hour immersion times as in Figure 10. The detail of QT_HMA $12.5 \mathrm{~mm}$ behavior is shown in Figure 11. The result leads to rethinking in consideration of the QT aggregates as the best aggregates for the asphalt mixture design of the 1 A national highway.

This can explain that lots of damages are observed in even cases of new asphalt pavements after long rainfall (about 35days) after many attempts to end the rutting and potholes, particularly the coastal region.

\section{CONCLUSIONS AND REMARKS}

The study was conducted to interpret the behavior of asphalt highway pavements under the extreme weather conditions with consideration of different aggregate types, HMA gradation, varying temperature and immersion time based on a series of the ID and UC tests and highway pavement failures observed on site. The results lead to the following conclusions:

The results of the aggregate types - temperature conditioning ID tests show that the HMA specimens employed granite aggregates are more temperature sensitive than the HMA specimens employed marble and limestone aggregates.

At higher temperature $60^{\circ} \mathrm{C}$ (in a tropical country like Vietnam) the HMA strength continues to reduce significantly. Thus, it is necessary to revise the appropriate temperature in asphalt design standard for the local condition to develop the adaptation asphalt pavement, especially under non-stationary future climate conditions, particularly for the NCC Region.

The results of the HMA specimens in the ID and UC tests subjected to both extreme temperature and immersion time (for modeling long duration rainfall about 3-5days) make people to consider using the granite aggregates for asphalt highway pavements in the similar weather conditions like the NCC region in Vietnam. High compression strength of the granite aggregates may not help to improve the bond strength of asphalt concrete due to the poor adhesion of asphalt granite aggregate systems in high temperature - water conditioning superposition.

The marble aggregates and limestone aggregates specimens of HMA $19 \mathrm{~mm}$ gradation are more stable than that of granite aggregates under shear stress in ID tests.

The HMA $12.5 \mathrm{~mm}$ gradation specimens are better than HMA $19 \mathrm{~mm}$ gradation specimens under the compression stress. In another word, it is better for the top layer of asphalt pavement where it serves directly loads of vehicle wheel.

The results of this study may be useful for pavement research in tropical climate region/countries.

\section{REFERENCES}

[1] R.C. Ahlrich, Influence of Aggregate Gradation and Particle Shape/Texture on Permanent Deformation of Hot Mix Asphal Pavements. Report of Army Engineer Waterways Experiment Station Vicksburg MS Geotechnical Lab. In Press (1996)

[2] Y. Altan, S. Sebnem, Water effect on deteriorations of asphalt pavements. The Online Journal of Science and Technology, Volume 2 , Issue 1 (2012)

[3] IPCC: Fourth assessment report (AR4): Climate change 2007. Contribution of working groups I, II and III to the fourth assessment report of the intergovernmental panel on climate change (IPCC), Cambridge University Press, Cambridge (2007)

[4] J.S. Daniel, J. M. Jacobs, E. Douglas, R.B. Mallick, K. Hayhoe, Impact of Climate Change on Pavement Performance: Preliminary Lessons Learned through the Infrastructure and Climate Network (ICNet). ASCE Construction Institute (2014)

[5] C.W. Schwartz, N. Gibson, R.A. Schapery, Time-temperature superposition for asphalt concrete at large compressive strains.Transportation Research Record, No. 1789, 101-112 (2002).

[6] T. Chompoorat, S. Likitlersuang, Temperature shift function of asphaltic concrete for pavement design in tropical countries. The IES Journal Part A: Civil \& Structural Engineering, Vol. 2, No. 3, August 2009, 246-254 (2009)

[7] J.P. Zaniewski, G. Srinivasan, Evaluation of Indirect Tensile Strength to Identify Asphalt Concrete Rutting Potential, Asphalt Technology Program, Department of Civil and Environmental Engineering, West Virginia University, Performed in Cooperation with the U.S. Department of Transportation - Federal Highway Administration (2004). 
[8] Bao Han. Rutting in extreme air temperature condition, reasons? http://baodatviet.vn/chinh-tri-xa-hoi/tin-tuc-thoi-su/duong-lun-do-nangnong-ai-chiu-toi-thay-ong-troi-3272723/. June 15th, 2017.

[9] MONRE report: Climate change scenarios and sea level rise for Vietnam (2012)

[10] N.N. Lan, P.D. Huu, D.N. Dong, Study on damage assessment of asphalted concrete surface in relation to buckling of slopes on some national highways of Vietnam. Journal of Transportation, August (2013).

[11] Xuan Hoa: May temperatures break Vietnam historical record http://vnexpress.net/print/thoisu/nhietdothang5phavohangloatkyluc3227972.html. June 2nd, 2015 